\title{
Limitações impostas à escolarização das crianças e adolescentes com doença falciforme
}

\section{Limitations imposed on schooling of children and adolescents with falciform disease}

\section{Limitaciones impuestas a la escolarización de los niños y adolescentes con enfermedad falciforme}

\author{
Lívia Custódio ${ }^{1}$ \\ Ilvana Gomes ${ }^{1}$ \\ Ilse Leitão ${ }^{1}$
}

DOI: http://dx.doi.org/10.20435/serie-estudos.v23i49.1128

\begin{abstract}
Resumo: A doença falciforme (DF) faz parte do grupo hemolítico, crônico e hereditário, avaliada como uma das principais e mais frequentes patologias de morbimortalidade significativas que acomete a população, possui grande diversidade de manifestação clínica, se apresentam através de uma série de complicações e sintomatologia que impactam diretamente a qualidade de vida do doente. O objetivo deste estudo foi conhecer as experiências e as limitações de crianças e adolescentes impostas pela doença falciforme à escolarização. De abordagem qualitativa, realizado em um hospital público de Fortaleza, com 16 crianças e adolescentes com diagnóstico da doença falciforme por meio de entrevista semiestruturada e a construção do desenho-estória, no período de maio a julho de 2016. Entre os achados, verificou-se que, durante o período em que a coleta de dados estava sendo realizada, todos os participantes estavam matriculados em uma escola. Ao apresentar a forma como enfrentam a doença, contatou-se, em alguns dos participantes, a necessidades deles em ter de se ausentar da sala de aula e da escola ou por conta da dor, advindas das crises vaso oclusivas, ou para realizar tratamento em prol da saúde. Conclui-se que a presença de sintomas dolorosos associados à doença falciforme levam a algumas implicações na vida das pessoas que padecem dessa enfermidade, principalmente no contexto escolar.
\end{abstract}

Palavras-chave: adolescente; criança; saúde escolar.

Abstract: Sickle cell disease (DF) is part of the hemolytic, chronic and hereditary group, evaluated as one of the main and most frequent pathologies of significant morbidity and mortality that affects the population, has a great diversity of clinical manifestations, present themselves through a series of complications and symptomatology which directly impact the quality of life of the patient. The objective of this study was to know the experiences and limitations of children and adolescents imposed by sickle cell disease on schooling. A qualitative approach was carried out in a public

\footnotetext{
${ }^{1}$ Universidade Estadual do Ceará (UECE), Fortaleza, Ceará, Brasil.
} 
hospital in Fortaleza, Brazil, with 16 children and adolescents diagnosed with sickle cell disease through a semistructured interview and the construction of the story-drawing from May to July 2016. Among the findings, it was found that, during the period in which data collection was being performed, all participants were enrolled in a school. But in presenting the way they cope with the disease, some of the participants were told about their need to be absent from the classroom and school or from pain, from occlusive vaso-occlusive crises, or from treatment for health. It is concluded that the presence of painful symptoms associated with sickle cell disease and constant treatments can lead to some implications in the lives of people suffering from sickness, especially in the school context.

Keywords: adolescent; child; school health.

Resumen: La anemia falciforme (DF) es parte del grupo hemolítico, crónico y hereditario, evaluada como una de las principales y más frecuentes patologías de morbilidad y mortalidad significativas que afecta a la población, presenta una gran diversidad de manifestaciones clínicas, se presenta a través de un serie de complicaciones y síntomas que afectan directamente la calidad de vida del paciente. El objetivo de este estudio fue conocer las experiencias y limitaciones impuestas por la enfermedad de células falciformes en la educación de niños y adolescentes. Se llevó a cabo un abordaje cualitativo en un hospital público en Fortaleza, Brasil, con 16 niños y adolescentes diagnosticados con anemia falciforme a través de una entrevista semiestructurada y la construcción de la historia de mayo a julio de 2016. Entre los hallazgos, fue descubrió que, durante el período en que se realizó la recopilación de datos, todos los participantes se inscribieron en una escuela. Pero al presentar la forma en que lidian con la enfermedad, a algunos de los participantes se les dijo acerca de su necesidad de ausentarse del aula y la escuela o sobre el dolor, las crisis oclusivas vaso-oclusivas o el tratamiento de salud. Se concluye que la presencia de síntomas dolorosos asociados con la enfermedad de células falciformes y los tratamientos constantes pueden llevar a algunas implicaciones en las vidas de las personas que padecen enfermedades, especialmente en el contexto escolar.

Palabras clave: adolescente; niño; salud escolar.

\section{INTRODUÇÃO}

A criança doente apresenta uma série de alterações orgânicas, emocionais e sociais que exigem, temporariamente ou permanentemente, demandas de cuidados específicos que, quando não são realizados adequadamente, interferem diretamente em sua sobrevivência (BARROS, 2016). Esse processo de adoecimento depende da complexidade da enfermidade, da gravidade, da fase e das estruturas disponíveis para com a terapêutica.

Em se tratando de doença crônica, o cuidado e a atenção devem ser redobrados e constantes, pois, segundo a Organização Mundial da Saúde (OMS, 2012), enfermidade dessa natureza acompanha o indivíduo por um longo período de anos ou décadas, apresenta momentos de piora ou melhora que requer gerenciamento 
e tratamento contínuos, os quais submetem o indivíduo a situações novas que acabam por alterar todo seu estilo de vida, sua rotina e seus relacionamentos.

Dos vários tipos de doenças crônicas, destaca-se neste artigo a doença falciforme (DF), que faz parte do grupo hemolítico caracterizada pela tendência de as hemácias a adquirirem, sob condições de baixa tensão de oxigênio, um formato anormal na estrutura ou na produção da hemoglobina, transformando-a em hemoglobina S (Hb S), a qual apresenta a forma de foice (CHAKRAVORTY; WILLIAMS, 2014).

Essa configuração de foice é avaliada como uma das principais e mais frequentes patologias hematológicas hereditárias de morbimortalidade significativas que acomete a população humana (CANÇADO; JESUS, 2007). Oriunda do continente africano, essa enfermidade pode ser encontrada em várias populações de diversas partes do mundo, inclusive no Brasil. Sua presença é mais predominante entre os afrodescendentes, com tendências a atingir parcelas cada vez mais significativas da população devido à existência do alto grau de miscigenação racial, podendo assim, alcançar indivíduos negros, pardos e brancos (ZAGO, 2001; CANÇADO; JESUS 2007; GESTEIRA; BOUSSO; RODARTE, 2016).

Estimativas apontam que essa enfermidade corresponde a $7 \%$ do total da população em todo o mundo (GOMES et al., 2014), o que leva a um cálculo de incidência de 300 a 400 mil crianças nascidas, por ano, acometidas com algum tipo de hemoglobinopatia (SANTOS et al., 2014). No Brasil, o Ministério da Saúde, em seus dados, apontam estimavas de mais de dois milhões de portadores do gene da hemoglobina Hb S (RODRIGUES; ARAUJO; MELO, 2010).

Por conta desses elevados índices, a doença falciforme é revestida como um problema de saúde pública, apresenta grande diversidade de manifestação clínica, caracterizada por meio de uma série de complicações e sintomatologia que se tornam complexas ao longo do seu desenvolvimento (BRITO et al., 2017). Tais manifestações estão subjacentes a dois principais mecanismos fisiopatogênicos: a hemólise e a vaso-oclusão, que terminam por lesar progressivamente os diversos tecidos e órgãos do organismo humano (MORRIS, 2008).

Esses eventos repetidos dolorosos da doença falciforme determinam vários problemas clínicos que exigem tratamento prolongado, com intervenções frequentes de acompanhamento nas unidades de saúde, mas, quando agravados, dependendo da gravidade da dor ou da crise dolorosa, os acometidos necessitam 
passar por internações hospitalares. Tais intercorrências, resultam em uma série de prejuízos que impedem o desenvolvimento sadio, implicam alterações na rotina diária e impactam diretamente na qualidade de vida das crianças e adolescentes, impondo-lhes uma série de limitações, tais como: prejuízo nas interações sociais, diminuição nas atividades físicas, além de ausência escolar (LORENCINI; PAULA, 2015).

Acredita-se que, diante dessas complexidades de sintomas, a criança e o adolescente ficam mais vulneráveis, vivenciam momentos desgastantes e estressores capazes de debilitar não só os aspectos físicos, mas outros aspectos como emocional, social e psicológico (SILVA et al., 2018).

Dessa forma, faz-se necessário que a sociedade, principalmente os profissionais que trabalham com essa população específica, sobretudo no campo da saúde e da educação, reconheçam as limitações impostas por essa doença e a forma com que eles enfrentam e lidam com a situação de adoecimento, a fim de prestar-Ihes uma melhor assistência e ajudá-los frente aos agravos que determinam, em algumas ocasiões, seu estado de saúde.

Dentro desse contexto, o objetivo do presente estudo foi conhecer as experiências e as vivências de adoecimento, bem como saber quais as limitações impostas pela doença falciforme à escolarização, a partir da perspectiva das crianças e dos adolescentes.

\section{METODOLOGIA}

Ao se propor conhecer as experiências e as vivências de adoecimento a partir da perspectiva das crianças e dos adolescentes com a doença falciforme, adotou-se uma metodologia de estudo exploratória, ancorando-se em uma abordagem qualitativa. Esta pesquisa foi um recorte de uma dissertação, e teve a intenção de investigar aspectos de uma situação não conhecida para obter mais informações sobre o objetivo em estudo, na tentativa de entender a realidade e trazer à tona aspectos subjetivos dos sujeitos em meio ao contexto em que estão inseridos, com um universo de significados, crenças e valores (MINAYO, 2014).

A coleta de dados ocorreu no período de maio a julho de 2016, em um ambulatório de uma unidade pediátrica, pública, de atenção terciária, referência em Fortaleza e em todo o estado do Ceará, com serviços de emergência, clínica e cirurgia em todas as especialidades voltadas exclusivamente às crianças e adolescentes. 
Participaram do estudo 16 crianças e adolescentes com diagnóstico da doença falciforme, na faixa etária de cinco a quinze anos de idade, que faziam acompanhamento ambulatorial e concordaram em participar do estudo. Com o intuito de manter o sigilo na identificação dos participantes deste estudo, eles foram identificados por letras e acompanhados de números ordinais, sendo crianças C1; e os adolescentes $A_{1}, A_{2}$ e $A_{3}$.

Para a realização do estudo, foram utilizadas as seguintes técnicas: observações; entrevista semiestruturada gravada, cujo roteiro contemplava aspectos de identificação dos participantes e uma questão norteadora: "Para você, como é ter esta doença?"; Como você fica na escola quando está em período de crise dolorosa? Com foco a atingir o objetivo do estudo; e a construção do desenho-estória de Trinca (1997), por considerar como o melhor material pelo qual se pode compreender a subjetividade das crianças, que envolve a sua vida, sua história, seu modo de ver e de pensar a realidade.

Após o consentimento e a assinatura do Termo de Assentimento Livre e Esclarecido (TALE), para as crianças e os adolescentes, e do Termo de Consentimento Livre e Esclarecido (TCLE), para o responsável legal, os adolescentes optaram por realizar a entrevista, enquanto que as crianças preferiram o desenho estória.

A técnica do desenho estória foi aplicada depois de estabelecido o contato entre a pesquisadora e o menor, para que a criança conhecesse a técnica. Em seguida, foi solicitada a produção de um único desenho, realizado em apenas um momento, de maneira livre, individual, em uma folha de papel ofício, cuja duração variou de criança para criança. Quando finalizado, ela/ele era convidado (a) a falar, esclarecer e/ou explicar sobre o que havia produzido, atribuindo assim o seu significado.

As entrevistas com os depoimentos dos adolescentes foram transcritas na íntegra, para posterior análise. Por ser uma entrevista realizada com um público infanto-juvenil, as questões foram adaptadas à compreensão e linguagem adequadas para a faixa etária em estudo, sendo solicitado e explorado para elas relatarem.

A análise dos dados ocorreu baseada à luz dos pressupostos básicos da análise de conteúdo de Bardin (2011) e da análise de conteúdo para desenhos de Coutinho (2011). Tais métodos obedecem à leitura flutuante dos discursos, exploração do material, identificação dos núcleos de sentido, categorização e 
tratamento dos resultados. Para a análise dos desenhos, acrescenta-se a separação dos desenhos por semelhanças gráficas à etapa de categorização. Após decodificação e categorização dos dados, emergiu uma grande categoria: Limitações impostas pela doença à escolarização.

O projeto desta pesquisa foi avaliado e aprovado pelo Comitê de Ética em Pesquisa da Universidade Estadual do Ceará (UECE) e do Hospital Infantil Albert Sabin (HIAS), onde os dados foram coletados, sob protocolo n. 1.547.314, em observância a Resolução n. 466/12, que trata das normas regulamentadoras de pesquisa envolvendo seres humanos.

\section{RESULTADOS E DISCUSSÕES}

\subsection{Caracterização dos participantes}

Dos 16 participantes da pesquisa, metade foi do sexo masculino, e a outra, feminina, o que correspondeu oito de cada sexo. No que diz respeito às faixas etárias, teve-se uma variação entre as idades de cinco até quinze anos de idade, sendo onze crianças e cinco adolescentes, conforme a delimitação apontada pelo Estatuto da Criança e do Adolescente (ECA), a qual retrata a criança como um cidadão de zero até 12 anos incompletos, e o adolescente com idade de 12 aos 18 anos (BRASIL, 2003).

Em relação à escolarização, verificou-se que todos os participantes estavam matriculados e frequentando a escola, durante o período em que a coleta de dados estava sendo realizada. No entanto ressalta-se que todos eles tiveram que passar por algumas ausências da sala de aula para realizar consultas médica, internações ou fazer algum tipo de tratamento devido à doença.

Quanto ao nível escolar em curso das crianças e adolescentes com doença falciforme, os resultados apontaram que três crianças estavam cursando a Educação Infantil (E. I.); sete estavam no Ensino Fundamental I (E. F. I), do 10 ao 5ㅇaㅇ ano seis encontravam-se no Ensino Fundamental II (E. F. II), do 6ㅇ ao 9o ano.

De acordo com a Lei n. 11.274, de 6 de fevereiro de 2006, que alterou a Lei de Diretrizes e Bases da Educação Nacional (LDB), o Ensino Fundamental no Brasil passou por uma série de mudanças, tais como o aumento do tempo destinado para a alfabetização, passando de oito para nove anos, com a obrigação da matrícula para crianças aos seis anos de idade. A primeira etapa da educação básica 
refere-se à educação infantil e, tem como finalidade o desenvolvimento integral da criança de zero até cinco anos de idade; enquanto que o Ensino Fundamental ocorre do 1으 ao 9o ano, com idades de 6 a 14 anos, cronologicamente um ano para cada série, sendo subdividido em dois: Ensino Fundamental I, de seis aos dez anos de idade; e o Ensino Fundamental II, dos onze aos 14 anos (BRASIL, 2006)

Portanto, consoante as Leis acima descritas que estabelecem os parâmetros preconizados pelo MEC, pode-se ressalvar que seis dos participantes estavam fora da faixa etária exigida, ou seja, estavam cursando um ano escolar inadequado para a sua faixa etária.

No tocante ao local de procedência das crianças e dos adolescentes, viu-se que oito habitavam no interior do Ceará, seis na capital, Fortaleza, CE, e dois na região metropolitana. Para aderir ao tratamento em relação a DF, dez deles precisavam se deslocar do interior ou da região metropolitana para a capital, pois onde eles moravam não tinham acompanhamento médico.

Por conseguinte, todos os participantes, ao receberem o diagnóstico de alguma hemoglobinopatia, com a constatação da presença de hemoglobina anômala nos glóbulos vermelhos, foram encaminhados para realizar seu fluxo terapêutico e tratamento no Hospital Albert Sabin (HIAS), unidade de referencia pediátrica do estado do Ceará.

\subsection{Limitações impostas pela doença à escolarização}

$\mathrm{Na}$ análise dos dados dos desenhos e relatos das crianças e adolescentes relacionados ao significado da condição vivenciada no processo de adoecimento, foi extraído e agrupado o núcleo de sentido, o qual emergiu uma grande categoria: limitações impostas pela doença à escolarização.

Ao apresentar a forma como enfrentam a doença, constatou-se, em alguns dos participantes, a necessidade deles em ter de se ausentar da sala de aula e da escola, ou por conta da dor, advindas das crises vaso oclusivas, ou para realizar tratamento em prol da saúde, conforme as colocações dos participantes abaixo.

[...] a doença atrapalha minha vida. Falto aula para ir pra consulta [...] Gosto muito de estudar, mas isso atrapalha nos estudos. ( $\mathrm{A}_{1}-15$ anos).

Essa doença é muito chata, moro no interior e tenho que dormir no hospital pra vir pro Sabin (para a consulta), perco muitas aulas [...] saímos de lá umas 3hs e volta só final da tarde ( $\mathrm{A}_{2}-14$ anos). 
A condição crônica de saúde acarretou limitações e modificações na rotina desses dois adolescentes, realidade demonstrada e que se apresentou como uma problemática no universo da doença e do tratamento em que eles estão inseridos, portanto são obrigados a encaixar-se a ela.

O tratamento adequado e o acompanhamento clínico são imprescindíveis para os indivíduos com doença falciforme, sua adesão os ajuda nas práticas de cuidado que estimulam a reduzir as complicações e promover longevidade com uma melhor qualidade de vida (BRASIL, 2015). Para tanto, apesar de existir essa necessidade de adesão ao tratamento, os adolescentes demonstram, por conta da doença, sentirem-se prejudicados, pois precisam se ausentar da escola.

Esse cenário de ausências da escola durante o período letivo também foi visto em algumas pesquisas (CASTELO et al., 2012; DIAS, 2013; BRITO et al., 2017), as quais constataram que os motivos alavancados pelos indivíduos sobre a necessidade de se ausentarem da escola são praticamente os mesmos, ou seja, são os sinais, os sintomas e as constantes crises de dor proporcionadas pela presença da Hemoglobina S ( $\mathrm{Hb} \mathrm{S}$ ), que faz com que crianças e adolescentes, frequentemente, sejam submetidos às consultas médicas, exames e até internações hospitalares, prejudicando assim suas vidas em diversas esferas, principalmente na vida escolar.

A partir da fala do adolescente $A_{1}$, verificou-se que ter a doença falciforme interferiu de maneira negativa em diferentes aspectos em sua vida, sobretudo nos aspectos relacionados ao seu desejo pelo estudo, uma vez que ele afirmou: [...] gosto muito de estudar, mas isso atrapalha nos estudos. A palavra "isso" se refere à doença falciforme.

Corroborando com essa ideia, viu-se que, na pesquisa de Ferreira et al. (2015), realizada em um hospital de referência pediátrica na cidade de Fortaleza, com crianças e adolescentes cronicamente adoecidos, os participantes expressaram existir, sim, prejuízos escolares durante o período de internação e adoecimento, e que, para eles, é muito difícil ter de se afastar do processo de ensino-aprendizagem, pois eles não gostaram de ficar sem estudar e sem aprender novidades.

Para o adolescente $A_{2}$, percebe-se que as suas ausências da escola também são ocasionadas devido à doença, mas ele aponta para a questão do deslocamento que precisa realizar para se consultar, sair do interior para a capital. Para essa condução acontecer, ele precisa sair de madrugada da cidade onde mora e 
voltar somente no final da tarde ou à noite, é um dia todo exclusivo para cuidar da sua saúde.

Para as pessoas que moram em cidades onde não há a especialidade médica de que eles necessitam, o deslocamento até a unidade de saúde pode ser complexificado, como foi o caso de $\mathrm{A}_{2}$ e, em uma pesquisa da Trindade (2016), a qual abordou experiências de pessoas com doenças reumáticas crônicas, com evidências de casos de pacientes que precisam se deslocar do interior do estado para a capital, Porto Alegre, com ônibus das prefeituras para realização de atendimentos da reumatologia nos hospitais. Para eles, os sintomas de doenças reumáticas envolvem dor e, consequentemente, limitação da mobilidade que leva à perda de um grande número de funções na vida diária, afetando, em maior ou menor grau, o deslocamento, o cuidado pessoal e outras atividades básicas.

$O$ advento de uma doença crônica traz à tona eventos inesperado que desencadeiam a organização e a reorganização da vida cotidiana desses indivíduos em razão dos frequentes cuidados com a saúde, seja na circunstância de internação, seja na circunstância do atendimento em serviços de atenção integral à saúde, como se observa neste relato a seguir.

Desde novinha tenho problemas [...] Me internava, tomava remédio, tomava sangue e voltava pra casa [...] Eu vivia nos hospitais, toda minha vida era lá, ninguém sabia o que eu tinha. [...] Não fazia outra coisa, não tinha vida $\left(\mathrm{A}_{4}-15\right.$ anos).

Nessa alocução, a adolescente não apresenta de maneira direta como $\mathrm{A}_{1}$ e $\mathrm{A}_{2}$ sobre as repercussões da enfermidade em atrapalhar sua vida no âmbito escolar, mas nas entrelinhas afirmou que "vivia nos hospitais, toda sua vida era lá. Não fazia outra coisa". Por meio dessas palavras, ela expressa que, desde muito cedo, a sua vida foi perpassada por vivências de adversidades dolorosas em hospitais, precisando de cuidados constantemente.

As manifestações clínicas, os sintomas e a dor na doença falciforme comprometem progressivamente os órgãos vitais ou a perda de suas funções e, dependendo da frequência e/ou intensidade, podem comprometer o exercício diário das pessoas que sofrem desse mal em consequência das suas vidas, contemplando os aspectos relacionados à sua vivência (KIKUCHI, 2007).

$\mathrm{O}$ estado de saúde de $\mathrm{A}_{4}$ parece ter comprometido vários aspectos em sua vida, principalmente, durante a sua infância, período importante para a 
constituição do sujeito, mas que, quando acompanhado de doença, compromete o desenvolvimento natural e apresenta maiores chances de se tornarem traumáticas, já que ela faz alusão ao que foi vivido e às marcas deixadas pelas experiências de desprazer (ZAVARONI; VIANA, 2015).

Para além da experiência de desprazer relatada por $\mathrm{A}_{4}$, ressalta-se ainda a falta de um diagnóstico preciso e precoce em torno da sua doença que a afastou de tudo, sem que nenhum profissional descobrisse o que ela tinha de fato. Essa ausência do diagnóstico verificado foi em contrapartida ao que foi preconizado pelo Ministério da Saúde, que evidencia pelo Programa Nacional de Triagem Neonatal (PNTN), popularmente conhecido no Brasil por "teste do pezinho", para orientação e investigação diagnóstica específica, permitindo a quantificação e o acompanhamento dos casos, bem como ajuda para o planejamento e a organização dentro da rede de atenção integral a saúde (BRASIL, 2014).

Quando as pessoas acometidas pela doença falciforme não são diagnosticadas precocemente, podem enfrentar uma série de sofrimentos, conforme foi constatado neste estudo e no de Xavier (2011). Elas podem ter uma série de complicações, como o sequestro esplênico, que desencadeará em vários processos infecciosos e dolorosos, os quais as obrigam a passar por uma série de procedimentos, sendo submetidas a tratamento sem resultados efetivos.

Outra experiência foi apresentada por uma criança de nove anos, demonstrando a repercussão que a doença Ihe trouxe em seu cotidiano, como se observa no desenho abaixo. 
Desenho 1 - Chorando de dor
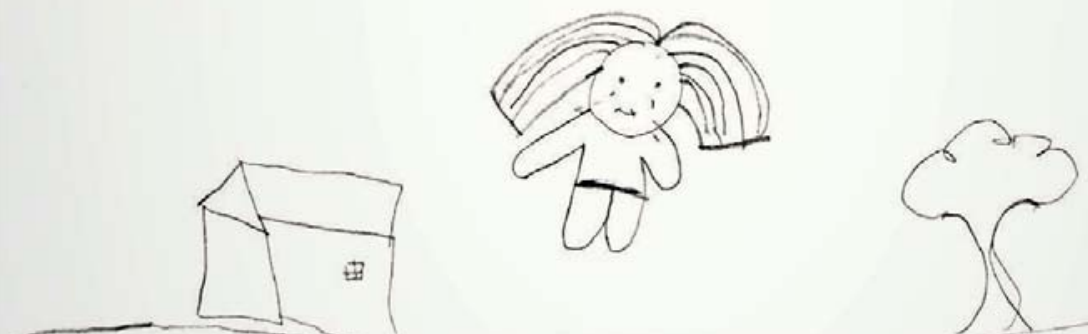

Fonte: Criança de 9 anos (C9).

Ao ser solicitada para explicar a sua produção, a criança falou por meio de poucas palavras, mas de maneira clara e objetiva.

- Isso é uma menina chorando, ela tá com dor [...] Muita dor [...] ela tava na escola, mas tem que ir embora. Ela não aguentou de dor.

Na tentativa de estimular mais a sua verbalização e entender melhor o desenho, indagou-se:

- Quem é "ela"?

- [...] Essa sou eu, chorando de dor.

- E, por que está chorando?

- Tá chorando por causa da dor.

Como foi visto, a menina se autodesenhou chorando por conta de uma crise dolorosa ocasionada pela doença falciforme, que sentiu quando ainda estava na escola, precisando assim se retirar e ir embora. A sua forma escolhida para articular sobre a sua condição de saúde penetra sobre a sua percepção em relação à dor e o afastamento.

Observa-se que a experiência de ter essa enfermidade tende a provocar na vida cotidiana dos que padecem desse mal, sobretudo na vida de crianças e adolescentes, um confronto com a dor, algo que lhes é muito comum e promove uma ruptura em seus estilos de vida, mudanças nos seus hábitos, além dos vários 
tipos de afastamentos que ocorrem, como da família, da escola e dos amigos (MARQUES; CAVALCANTI; RUZZI-PEREIRA, 2015).

Schneider e Martini (2011) afirmam que crianças e adolescentes com doença crônica têm o seu cotidiano modificado devido à duração do tratamento e as frequentes hospitalizações que comprometem a vida escolar. Isso traz uma série de consequências que acarretam em afastamento da escola, prejuízos no acompanhamento do ano escolar, alterações no desempenho, no aprendizado que levam ao atraso escolar.

Pinto et al. (2017), em pesquisa realizada com as mães de crianças com doenças crônicas, comprovaram que, segundo relato delas, a doença de seus filhos impõe limitações e dificuldades para a permanência na escola, eles passam por muitas ausências devido a reincidentes idas às clínicas e/ou hospitalizações repetitivas, ressaltaram ainda que as especificidades de saúde deles não são respeitadas como deveriam e que eles são menos contemplados no processo de ensino aprendizagem em relação aos demais.

Outra criança também abordou sobre a questão do afastamento e a modificação em seu cotidiano por ocasião da doença, conforme se observa abaixo.

Desenho 2 - Em busca de cuidado

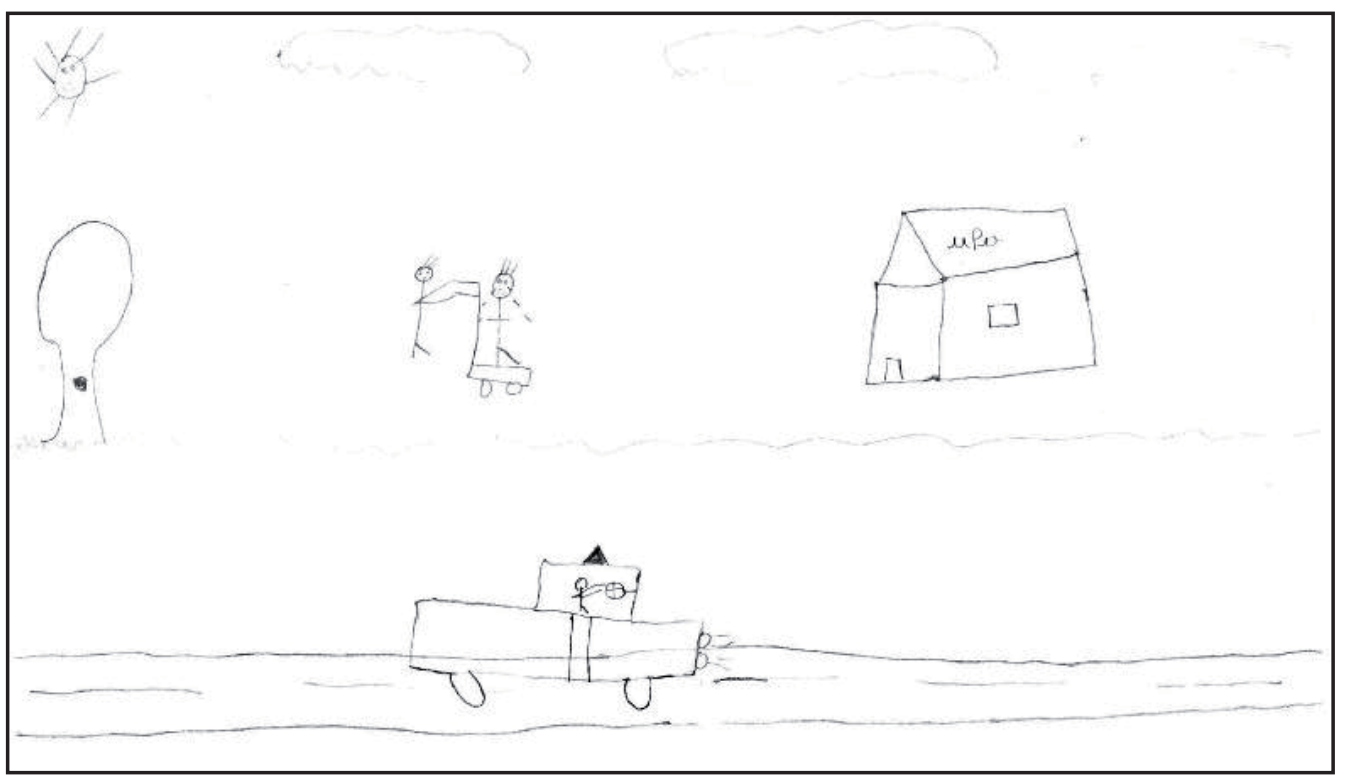

Fonte: Criança de 7 anos (C2). 
O esclarecimento de C2 sobre a sua atividade simbólica foi:

- Isso aqui é um boneco, ele tá sendo levando pela mãe pra UPA [...] tá indo com muita dor. Ele tá chorando, dói muito e minha mãe me leva.

Depois apontando para o homem no carro, completou:

- No meio do caminho ela para esse táxi e leva nois pra UPA [...] é ruim porque dói tudo, dói o corpo, dói a perna [...] fico doido pra chegar logo na UPA, o mais rápido, pra melhorar.

- Onde você estava?

- Tava na escola. Comecei a sentir a dor [...].

- Como a sua mãe foi até lá, na escola?

- A minha professora me viu chorando e ligou pra ela. Aí ela foi correndo e me pegou.

De acordo com o que foi dito, inicialmente, a criança se apresenta como um boneco, mas ao decorrer da frase ela se implica na fala e diz que foi a mãe que o levou para a emergência de uma unidade de saúde, chamada de Unidade de Pronto Atendimento (UPA), em busca de assistência e vislumbrando melhorar da dor que sentia.

Essa informação vem ao encontro sobre o que foi estabelecido pelo Ministério da Saúde dos atendimentos que, geralmente, são realizados nas UPAs, devendo seguir uma classificação estabelecida conforme o protocolo de acolhimento e classificação de risco, avaliando diversos aspectos do paciente e situação local de prioridade (BRASIL, 2004).

A representação do desenho mostra outro episódio de rompimento com o cotidiano, que fez com que $\mathrm{C}_{2}$ saísse correndo devido uma crise dolorosa muito forte sentida e que aconteceu de maneira inesperada. A necessidade de um atendimento de urgência foi exposta por essa criança com crise de falcização, para tanto se acrescenta a consideração que se deve ter sobre a intervenção relacionada ao manejo dessa dor e, assim considerar o atendimento de elevada prioridade.

No entanto resguarda-se que a sequência de um tratamento longo, em razão dos frequentes episódios de dor, faz com que a criança, se já estiver inserida no ambiente escolar, perca muitos mais dias de aula do que a maioria das crianças, podendo ocorrer até mesmo atrasos, interrupção ou abandono dos estudos para seguir a terapêutica (BARRIGA et al., 2012). 
Somado a esse atraso escolar, existe ainda a possibilidade de haver prejuízos significativos encontrados no desempenho intelectual, funções executivas, linguagem, memória e habilidade visoespacial que comprometem cognitivamente esse adolescente falcêmico ou o influencia com maior predisposição para eventos neurológicos e demais fatores relacionados à doença (KRAL et al., 2006; MACKIN et al., 2014; RUFFIEUX et al., 2013).

\section{CONSIDERAÇÕES FINAIS}

Os achados da pesquisa refletem as experiências e as vivências de adoecimento, principalmente, no que diz respeito às limitações impostas pela doença falciforme à escolarização a partir da perspectiva das crianças e dos adolescentes.

As representações demonstradas pelos desenhos e falas dos participantes possibilitaram a compreensão da repercussão e prejuízos por causa das manifestações clínicas e complicações da enfermidade que proporciona impactos significativos em diferentes esferas de suas vidas, principalmente no contexto escolar.

Frente às experiências observadas desta pesquisa, de impossibilidade de frequência à escola por condições e limitações específicas de saúde, sugere-se a implantação do atendimento pedagógico em ambientes hospitalares, uma vez que a educação é um direito conquistado por meio da Constituição Federal Brasileira. Reorganizar a assistência hospitalar de modo a cumprir com os direitos à saúde e à educação, respeitando o paradigma de inclusão, contribuindo para com a humanização e assegurando o acesso de atenção às necessidades educacionais especiais, de modo a promover o desenvolvimento e contribuir para a construção do conhecimento dessas crianças e adolescentes.

Acreditamos que os resultados deste estudo poderão nortear a conduta dos profissionais que trabalham com esse público, sobretudo os profissionais do campo da educação, na construção de estratégias que subsidiarão uma melhor assistência prestada com o intuito de diminuir sofrimentos como os aqui relatados.

\section{REFERÊNCIAS}

BARDIN, Laurence. Análise de conteúdo. São Paulo: Edições 70, 2011.

BARRIGA, Francisco et al. Hematopoietic stem cell transplantation: clinical use and perspectives. Biological Research, v. 45, n. 3, p. 307-16, 2012. 
BARROS, Ana Beatriz S. de. Dúvidas dos familiares de crianças com necessidades especiais de saúde quanto os cuidados domiciliares. 71 f. Monografia (Graduação em Enfermagem) - Universidade Federal Fluminense (UFF), Rio de Janeiro, 2016.

BRASIL. Ministério da Saúde. Secretaria de Atenção à Saúde. Departamento de Atenção Hospitalar e de Urgência. Doença falciforme: diretrizes básicas da linha de cuidado. Brasília: Ministério da Saúde, 2015.

- Ministério da Saúde. Secretaria de Atenção à Saúde. Doença Falciforme: Hidroxiureia, uso e acesso. Brasília: Ministério da Saúde, 2014. Disponível em: <http:// bvsms.saude.gov.br/bvs/publicacoes/doenca_falciforme_hidroxiureia_uso_acesso.pdf>. Acesso em: 5 maio 2017.

. Portaria 399/GM de 22 de fevereiro de 2006. Divulga o pacto pela saúde 2006consolidação do SUS e aprova as diretrizes operacionais do referido pacto. Ministério da Saúde. Diário Oficial da República Federativa do Brasil, Brasília, 2006.

. Ministério da Saúde. Secretaria de Atenção à Saúde. Humaniza SUS: acolhimento com avaliação e classificação de risco: um paradigma ético-estético no fazer em saúde. Brasília: Ministério da Saúde, 2004.

. Estatuto da criança e do adolescente. 4. ed. Brasília: Câmara dos Deputados, 2003.

BRITO, Neusa et al. A doença crônica no contexto escolar: os saberes de alunos com Anemia Falciforme. Revista de Educação Pública, v. 26, n. 62/2, p. 675-93, maio/ ago. 2017. Disponível em: <http://www.periodicoscientificos.ufmt.br/ojs/index.php/ educacaopublica/article/view/5507/3629>. Acesso em: 19 set. 2017.

CANÇADO, Rodolfo D.; JESUS, Joice A. A doença falciforme no Brasil. Revista Brasileira de Hematologia e Hemoterapia, São José do Rio Preto, SP, v. 29, n. 3, p. 204-6, jul./set. 2007.

CASTELO, Natália de M. et al. Anemia falciforme sobre o olhar de pessoas com a doença no Amapá. Ciência Equatorial, Natal, RN, v. 2, n. 2, 2012.

CHAKRAVORTY, Subarna; WILLIAMS, Thomas N. Sickle cell disease: a neglected chronic disease of increasing global health importance. Archives Disease in Childhood, v. 100, p. 48-53, 2015. Disposnivel em: <http://adc.bmj.com/content/early/2014/09/19/ archdischild-2013-303773>. Acesso em: 19 set 2017.

COUTINHO, Maria P. L. Métodos de pesquisa em psicologia social: perspectivas qualitativas e quantitativas. João Pessoa: UFPB/Editora Universitária, 2011.

DIAS, Ana L. A. A (re) construção do caminhar: itinerário terapêutico de pessoas com Doença Falciforme com histórico de úlcera de perna. 2013. Dissertação (Mestrado em Saúde Coletiva)- Instituto de Saúde Coletiva, Universidade Federal da Bahia (UFBA), Salvador, 2013.

FERREIRA, Mayara K. M. et al. Criança e adolescente cronicamente adoecidos e a escolarização durante a internação hospitalar. Trabalho, Educação e Saúde, Rio de Janeiro, v. 13, n. 3, p. 639-55, set./dez. 2015. 
GESTEIRA, Elaine C. R.; BOUSSO, Regina S.; RODARTE, Alzilid C. Uma reflexão sobre o manejo familiar da criança com doença falciforme. Revista de Enfermagem do Centro-Oeste Mineiro (RECOM), São João del Rei, MG, v. 6, n. 3, p. 2454-62, set./dez. 2016.

GOMES, Ludmila M. X. et al. Acesso e assistência à pessoa com anemia falciforme na Atenção Primária. Acta Paulista de Enfermagem, São Paulo, v. 27, n. 4, p. 348-55, 2014.

KRAL, Mary C. et al. Radiographic predictors of neurocognitive functioning in pediatric sickle cell disease. Journal of Child Neurology, v. 21, n. 1, p. 37-44, jan. 2006.

KIKUCHI, Berenice A. Assistência de enfermagem na doença falciforme nos serviços de atenção básica. Revista Brasileira de Hematologia e Hemoterapia, São José do Rio Preto, SP, v. 29, n. 3, p. 331-8, 2007.

LORENCINI, Grace R. F.; PAULA, Kely M. P. de. Perfil comportamental de crianças com anemia falciforme. Temas em Psicologia, Ribeirão Preto, SP, v. 23, n. 2, p. 269-80, 2015.

MACKIN, Scott et al. Neuroimaging abnormalities in adults with sickle cell anemia Associations with cognition. Neurology, v. 82, n. 10, p. 835-41, mar. 2014.

MARQUES, Larissa N.; CAVALCANTI, Alessandra; RUZZI-PEREIRA, Andrea. O viver com a doença falciforme: percepção de adolescentes. Revista de Terapia Ocupacional da Universidade de São Paulo, São Paulo, v. 26, n. 1, p. 109-17, jan./abr. 2015. Disponível em: <https://www.revistas.usp.br/rto/article/viewFile/52376/96500>. Acesso em: 10 dez. 2017.

MINAYO, Maria C. (Org.). Pesquisa social: teoria, método e criatividade. Petrópolis, RJ: Vozes, 2014.

MORRIS, Claudia R. Mechanisms of vasculopathy in sickle cell disease and thalassemia. Hematology. The Education Program of the American Society of Hematology American Society of Hematology Education Program. Hematology, v. 2008, n. 1, p. 177-85, 2008.

ORGANIZAÇÃO MUNDIAL DA SAÚDE (OMS). O cuidado das condições crônicas na atenção primária a saúde: o imperativo na consolidação da estratégia da saúde da família. Brasília, DF, 2012.

PINTO, Maria Benegelania et al. Perception of mothers about the school inclusion of children with chronic disease. Journal of Nursing UFPE on line, Recife, v. 11, n. 3, p. 1200-6, mar. 2017. ISSN 1981-8963. Disponível em: <https://periodicos.ufpe.br/revistas/ revistaenfermagem/article/view/13495>. Acesso em: 6 maio 2018.

RODRIGUES, Carmen C. M.; ARAUJO, Izilda E. M.; MELO, Luciana L. A família da criança com doença falciforme e a equipe enfermagem: revisão crítica. Revista Brasileira de Hematologia e Hemoterapia, São Paulo, v. 32, n. 3, p. 257-64, 2010. Disponível em <http:// www.scielo.br/scielo.php?script=sci_arttext\&pid=S1516-84842010000300013\&lng=en\& $\mathrm{nrm}=\mathrm{iso}>$. Acesso em: 19 maio 2018. 
RUFFIEUX, Nicolas et al. Association between biological markers of sickle cell disease and cognitive functioning amongst Cameroonian children. Child Neuropsychology, v. 19, n. 2, p. 143-60, 2013.

SANTOS, Pâmella N. D. et al. Anemia Falciforme: caracterização dos pacientes atendidos em um ambulatório de referência. Cogitare Enfermagem, Curitiba, PR, v. 19, n. 4, p. 78593, out./dez. 2014.

SCHNEIDER, Karine L. K.; MARTINI, Jussara G. Cotidiano do adolescente com doença crônica. Texto \& Contexto - Enfermagem, Florianópolis, v. 20, número especial, p. 194204, 2011.

SILVA, Ariana K. L. S. da et al. Renda e cor de pessoas com anemia falciforme atendidas na fundação Hemopa, Pará, Amazônia, Brasil: realidade e perspectivas. Revista da Associação Brasileira de Pesquisadores/as Negros/as (ABPN), Goiânia, v. 10, n. 24, p. 366-91, 2018. Disponível em: <http://abpnrevista.org.br/revista/index.php/revistaabpn1/article/ view/456>. Acesso em: 6 maio 2018.

TRINCA, Walter. Formas de investigação clínica em psicologia: procedimento de desenhosestórias: procedimento de desenhos de família com estórias. São Paulo: Vetor, 1997.

TRINDADE, Juliana de O. Doença como condição social: um estudo sobre as experiências de portadores de doenças reumáticas crônicas em Porto Alegre. 2016. Dissertação (Mestrado em Ciências Sociais) - Pontifícia Universidade Católica do Rio Grande do Sul (PUCRS), Porto Alegre, 2016.

XAVIER, Aline S. G. Experiências reprodutivas de mulheres com anemia falciforme. 2011. Dissertação (Mestrado em Enfermagem) - Universidade Federal da Bahia (UFBA), Salvador, 2011.

ZAGO, Marco A. Anemia falciforme e doenças falciformes. In: BRASIL. Ministério da Saúde. Secretaria de Políticas de Saúde. Manual de doenças mais importantes, por razões étnicas, na população brasileira afrodescendente. Brasília: Ministério da Saúde, 2001.

ZAVARONI, Dione de Medeiros Lula; VIANA, Terezinha Camargo. Trauma e infância: considerações sobre a vivência de situações potencialmente traumáticas. Psicologia: Teoria e Pesquisa, Brasília, v. 31, n. 3, p. 331-38, jul/set. 2015.

\section{Sobre as autoras:}

Lívia Custódio: Graduação em Pedagogia pela Universidade Federal do Ceará (UFC) e Psicologia pela Universidade de Fortaleza (UNIFOR). Mestrado em Saúde Coletiva pela Universidade Estadual do Ceará. Professora da Faculdade da Aldeia de Carapicuiba (FALC). Membro participante do grupo de pesquisa: Doenças crônicas em crianças e adolescentes, família, saúde coletiva e enfermagem (CRACROFS), 
nos seguintes temas: criança hospitalizada; doença crônica infanto juvenil, doença falciforme, humanização da assistência, política de saúde e defesa da criança e do adolescente. E-mail: liviacustodio@yahoo.com.br

Ilvana Gomes: Mestrado em Enfermagem em Saúde Comunitária pela Universidade Federal do Ceará. Doutorado em Saúde Coletiva pela Universidade do Estado do Rio de Janeiro/Instituto de Medicina Social, e pós-doutorado pela Universidade Federal da Bahia/Instituto de Saúde Coletiva. Professora Adjunta da Universidade Estadual do Ceará, coordenadora do Comitê de Ética em Pesquisa do Hospital Geral de Fortaleza e enfermeira na Secretaria de Saúde do Estado do Ceará. Lider do grupo de pesquisa: Doenças crônicas em crianças e adolescentes, família, saúde coletiva e enfermagem (CRACROFS). E-mail: ilverde@gmail.com

Ilse Leitão: Graduação em Enfermagem pela Universidade Federal do Ceará. Mestrado em Saúde Pública pela Universidade Estadual do Ceará e doutorado em Saúde Coletiva pela Associação Ampla - UECE - UFC- UNIFOR pela Universidade Estadual do Ceará. Professora adjunta do Programa de Pós-Graduação em Saúde Coletiva e do Mestrado Profissional em Gestão em Saúde da Universidade Estadual do Ceará, professora do Instituto de Estudos, Pesquisas e Projetos da UECE, e professora da Associação Brasileira de Enfermagem (ABEn-CE). Líder do Grupo de pesquisa Gestão do trabalho e da segurança dos processos organizacionais em saúde e enfermagem. E-mail: ilse.tigre@uece.br

\section{Recebido em fevereiro de 2018.}

Aprovado em maio de 2018. 